\title{
Impact of Agulhas Leakage on the Atlantic Overturning Circulation in the CCSM4
}

\author{
WILBERT WEIJER \\ Los Alamos National Laboratory, and the New Mexico Consortium, Los Alamos, New Mexico \\ ERIK VAN SEBILLE \\ Climate Change Research Centre, and ARC Centre of Excellence for Climate System Science, \\ University of New South Wales, Sydney, New South Wales, Australia
}

(Manuscript received 30 September 2012, in final form 25 July 2013)

\begin{abstract}
The impact of Agulhas leakage variability on the strength of the Atlantic meridional overturning circulation (AMOC) in the Community Climate System Model, version 4 (CCSM4) is investigated. In this model an advective connection exists that transports salinity anomalies from the Agulhas region into the North Atlantic on decadal (30-40 yr) time scales. However, there is no identifiable impact of Agulhas leakage on the strength of the AMOC, suggesting that the salinity variations are too weak to significantly modify the stratification in the North Atlantic. It is argued that this study is inconclusive with respect to an impact of Agulhas leakage on the AMOC. Salinity biases leave the South Atlantic and Indian Oceans too homogeneous, in particular erasing the observed salinity front in the Agulhas retroflection region. Consequently, salinity variability in the southeastern South Atlantic is found to be much weaker than observed.
\end{abstract}

\section{Introduction}

Coupled climate models are routinely used to study internal variability and externally forced changes of the climate system. A crucial role is ascribed to the Atlantic meridional overturning circulation (AMOC), which plays an important role in the earth's heat balance by transporting heat northward across every latitude in the Atlantic Ocean (e.g., Trenberth and Solomon 1994); understanding the controls on its stability and variability is therefore a main thrust of climate research. Agulhas leakage is thought to be one of those controls. Agulhas leakage is the exchange of warm and salty waters from the Indian to the Atlantic Ocean, mainly through the shedding of large Agulhas rings (e.g., De Ruijter et al. 1999). In a recent review paper, Beal et al. (2011) explored existing evidence that Agulhas leakage may impact the global climate system, as it could affect the strength (Weijer et al. 1999, 2002; van Sebille and van Leeuwen 2007), stability (Weijer et al. 2001), and variability (Biastoch et al. 2008;

Corresponding author address: Wilbert Weijer, Los Alamos National Laboratory, CCS-2, MS B214, Los Alamos, NM 87545. E-mail: wilbert@lanl.gov
Biastoch and Böning 2013) of the AMOC. Particularly tantalizing are studies suggesting that resumption of Agulhas leakage during glacial terminations may have contributed to the recovery of the AMOC after glacial periods (Berger and Wefer 1996; Knorr and Lohmann 2003; Peeters et al. 2004).

Dynamically, Agulhas leakage can impact the stratification in the Atlantic through the introduction of temperature and salinity anomalies into the southeastern South Atlantic. Weijer et al. (2002), for instance, show that the adjustment takes place in two stages. The first stage is through rapid, $O$ (years) wave adjustment involving Rossby and Kelvin waves (van Sebille and van Leeuwen 2007; Biastoch et al. 2008; Heimbach et al. 2011). However, the efficiency of this interhemispheric influence on short, intradecadal time scales was questioned by Johnson and Marshall (2002a,b, 2004), who showed that the equator acts as a low-pass filter to crosshemispheric communications; a Southern Hemispheric impact on North Atlantic overturning can be expected on decadal time scales only. The second stage is an advective $O$ (decades) transport of the anomalies into the North Atlantic. In particular, Weijer et al. (2002) identify a mechanism through which an anomaly in 
temperature and salinity that is initially density compensated loses its thermal signature, and develops a density anomaly on its way north. Biastoch and Böning (2013) observe such a densification in their model in response to an increase in Agulhas leakage; however, they could not unequivocally ascribe a weak change in the strength of the AMOC to leakage-induced changes in the stratification.

The spatial resolution of the current generation of climate models, however, does not allow for an explicit representation of the process of Agulhas ring shedding. Instead, the Indian-Atlantic interocean exchange takes place in a viscous boundary layer (De Ruijter 1982), leading to a significantly stronger volume transport. Indeed, Weijer et al. (2012) report a mean $43 \mathrm{~Sv}$ volume exchange $\left(\mathrm{Sv} \equiv 10^{6} \mathrm{~m}^{3} \mathrm{~s}^{-1}\right)$ in the twentieth-century runs of the latest (fourth) version of the Community Climate System model (CCSM4), which is about threefold the $15 \mathrm{~Sv}$ rate inferred from observations (e.g., Richardson 2007). With the Indian-Atlantic Ocean connection fully open, rather than being choked off by a leaky retroflection, it is not clear to what extent variability in Agulhas leakage affects the strength of the AMOC in these coupled climate models. Here, we will explore this question by analyzing five centuries of a preindustrial control integration of the CCSM4. To the best of our knowledge, this is the first study to address the impact of Agulhas leakage on the strength of the AMOC in a fully coupled climate model.

\section{Analysis}

For this study we use output from the Community Climate System Model, version 4 (Gent et al. 2011). The CCSM4 is a fully coupled climate model; it consists of submodels for the different climate components, which communicate through a flux coupler. The ocean component is the Parallel Ocean Program (Smith et al. 2010). For the analysis presented in this paper, we use monthly averaged fields from the last 500 years of the 1850 preindustrial control integration of CCSM4. The spatial resolution of the ocean model is nominally $1^{\circ}$. In addition to the Lagrangian diagnostics described below, we analyze time series of AMOC transport, defined as the maximum value of the overturning streamfunction as function of latitude in the Atlantic Ocean. The mean overturning strength at $26.5^{\circ} \mathrm{N}$ is $20.1 \mathrm{~Sv}$, which compares well with the $18.7 \pm 5.6 \mathrm{~Sv}$ observed by Cunningham et al. (2007) at that latitude. The mean AMOC at $35^{\circ} \mathrm{S}$ is $18.4 \mathrm{~Sv}$. For the analysis presented here, salinity is averaged over the upper $1500 \mathrm{~m}\left(S_{1500}\right)$. Analyses with salinity averaged over the upper 150,750 , and $1000 \mathrm{~m}$ and the interval $750-1500 \mathrm{~m}$ yield similar results and will not be discussed here.

Agulhas leakage is estimated here using a Lagrangian particle tracking approach (e.g., van Sebille et al. 2010).
The design of the Lagrangian experiment is very similar to that described by Weijer et al. (2012), who studied Agulhas leakage in the twentieth-century runs of the same model. Here, over the 500 years of the 1850 preindustrial control integration, a total of $2.4 \times 10^{6}$ particles are released in the Agulhas Current and each of them is advected for 100 years using the Connectivity Modeling System (Paris et al. 2013). Figure 1 shows some of the calculated trajectories in the Atlantic Ocean. The Agulhas leakage is then diagnosed by keeping track of when each float last crosses the so-called Good Hope line. The Good Hope line is an oceanographic monitoring section that stretches from Cape Town southwestward through the Cape Basin, and then south to about $60^{\circ} \mathrm{S}$ along the Greenwich meridian (black lines in Fig. 1). It was designed to monitor the water mass exchanges between the Atlantic and Indian Ocean (Ansorge et al. 2005; Speich and Arhan 2007; Gladyshev et al. 2008).

Coarse-resolution ocean models such as the ocean component of the CCSM4 do not explicitly represent the mesoscale eddy field. Instead, its implied transports are parameterized by the parameterization of Gent and McWilliams (1990). The particles here only see the mean Eulerian velocity field and hence miss the more or less random dispersion implied by an active eddy field. Such dispersion can be modeled as a diffusion term in our Lagrangian analysis. To gauge the effects of subgrid-scale variability on the results, we repeated the calculations with an additional diffusion of $100 \mathrm{~m}^{2} \mathrm{~s}^{-1}$ to the trajectories. However, the results of this run with diffusion are very similar to the results without any diffusion added, and will not be discussed further.

The average volume flux across the Good Hope line is defined as $V_{\mathrm{ag}}(t)=\sum_{i} V_{i}$, hence the sum of all volumes $V_{i}$ associated with particles that cross the Good Hope section in any given month (Fig. 2a); the mean transport in this 1850 preindustrial control run is $34 \mathrm{~Sv}$. This is slightly lower than the $43 \mathrm{~Sv}$ in the twentieth-century runs of CCSM4 as reported by Weijer et al. (2012). In addition to its volume flux, Agulhas leakage can also be characterized by the heat and salt fluxes that it generates. In fact, previous studies (Weijer et al. 2002) suggest that salinity anomalies introduced by Agulhas leakage might be the most important factor in influencing the AMOC, as they perturb the stratification of the South Atlantic Ocean without significant damping by the atmosphere. Here, we measure Agulhas leakage as the flux of salinity anomalies $F_{S}$ (Fig. 2b); monthly values of $F_{S}(t)$ are calculated as $\sum_{i} V_{i}\left(S_{i}-S_{0}\right)$, hence summing over all particles that cross the Good Hope section in a given month with volume $V_{i}$ and salinity $S_{i}$.

The choice for $S_{0}$ is not obvious but, since $F_{S}$ strongly depends on its value, it has to be chosen carefully; for 


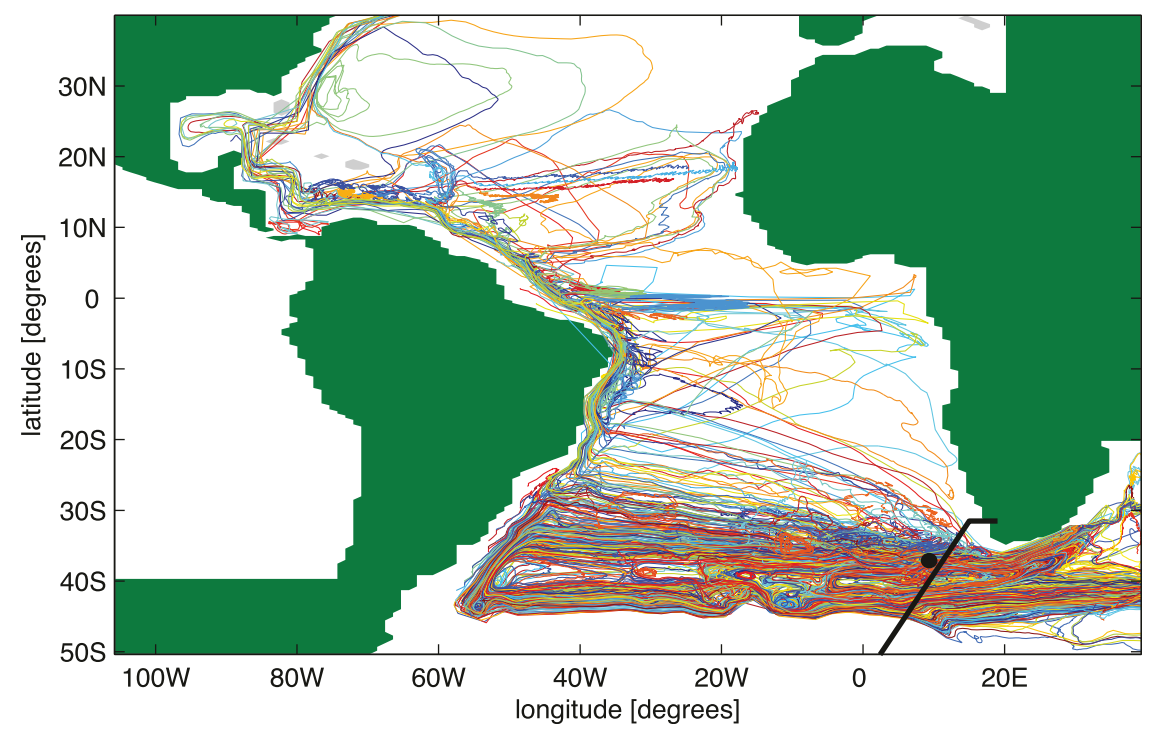

FIG. 1. Trajectories of 419 particles released on 15 Jan of model year 810 at $32^{\circ} \mathrm{S}$ in the Agulhas Current. The black line indicates the Good Hope line; trajectories crossing this line are assumed to have "leaked" into the Atlantic. The black dot indicates our reference location, at $37^{\circ} \mathrm{S}, 10^{\circ} \mathrm{E}$

any choice of $S_{0}$ that deviates however slightly from the time- and section-averaged salinity on the Good Hope section $\left(\left\langle\bar{S}_{\mathrm{GH}}\right\rangle\right.$, where the overbar denotes a time average and the angle brackets denote section average) $F_{S}$ will be dominated by the contribution $V_{\mathrm{ag}}(t)\left(\left\langle\bar{S}_{\mathrm{GH}}\right\rangle-S_{0}\right)$. There are a few problems with this: 1$)$ the fact that the choice for $S_{0}$ is not obvious (arguments can be made for an average over the full Atlantic, the South Atlantic only, or maybe even a regional average over the southeastern South Atlantic) introduces an arbitrariness to our analysis; and 2) the salt flux is dominated by transport fluctuations advecting the section-averaged salinity. A substantial part of this salt input may simply be recirculated in the subtropical gyre without affecting the density field in a meaningful way. In addition, the impact of salinity fluctuations of the leakage are effectively ignored, and thus 3 ) a constant value of $S_{0}$ will lead to positive and negative salt fluxes across different parts of the Good Hope section, due to spatial variations (mainly as function of depth) in the mean salinity on this section.

To alleviate these problems, we choose $S_{0}$ here to be the time-averaged salinity over the Good Hope section, $\bar{S}_{\mathrm{GH}}(x, z)$ (van Sebille et al. 2010). So, for each float that crosses the Good Hope section, its salinity is measured against the mean salinity at the crossing location. Salt flux variations will now be induced only by the mean transport advecting salinity anomalies, and by covariance of transport and salinity anomalies; fluctuations in volume transport in itself will not generate variability in $F_{S}$, just as would be expected in the real ocean where
Agulhas leakage that does not import excess salt will likely not affect the dynamics of the AMOC. Consistent with our choice of $S_{1500}$, we use only particles that cross the Good Hope line in the upper $1500 \mathrm{~m}$. In addition, we exclude floats in the upper $150 \mathrm{~m}$, which are influenced by the mixed layer and whose thermohaline characteristics are hence not conserved.

\section{Results}

\section{a. Agulhas leakage impact on the AMOC}

An analysis of the coherence (e.g., section 11.4 in von Storch and Zwiers 1999) between the two time series (Fig. 3a) shows that the volume flux $V_{\text {ag }}$ does not affect the salinity in the southeastern Atlantic Ocean, as represented here by a reference salinity time series $S_{1500}^{\text {ref }}$ (salinity at $37^{\circ} \mathrm{S}, 10^{\circ} \mathrm{E}$ in the South Atlantic, averaged over the upper $1500 \mathrm{~m}$; Fig. 2c). The associated salt transport $F_{S}$, however, is significantly coherent with $S_{1500}^{\text {ref }}$ for a wide range of frequencies. This suggests that in this model the salinity in the southeastern South Atlantic is affected by the upstream salinity variability in the Indian Ocean rather than changes in the actual volume flux, justifying the choice for $S_{0}=\bar{S}_{\mathrm{GH}}(x, z)$ discussed in the previous section.

Second, we study the meridional coherence of the AMOC to see whether and, if so, on what time scales interhemispheric communication of the AMOC can be expected. Figure $2 \mathrm{~d}$ shows the time series of AMOC 
a)

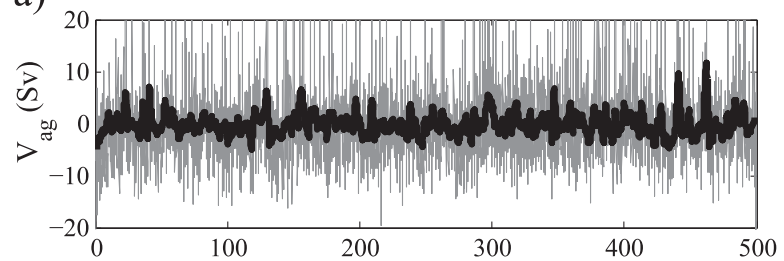

b)

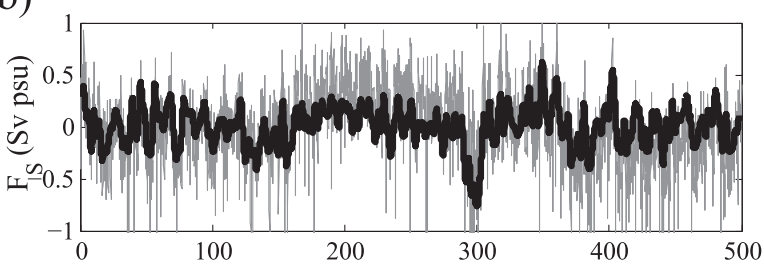

c)

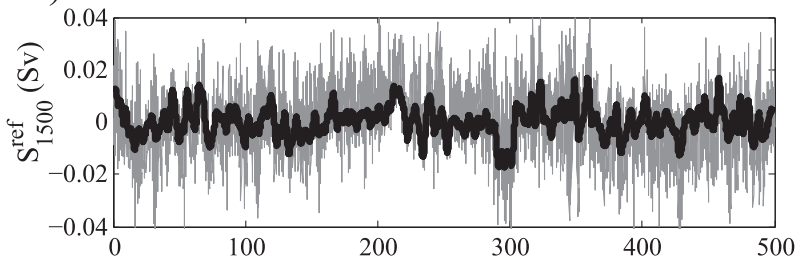

d)

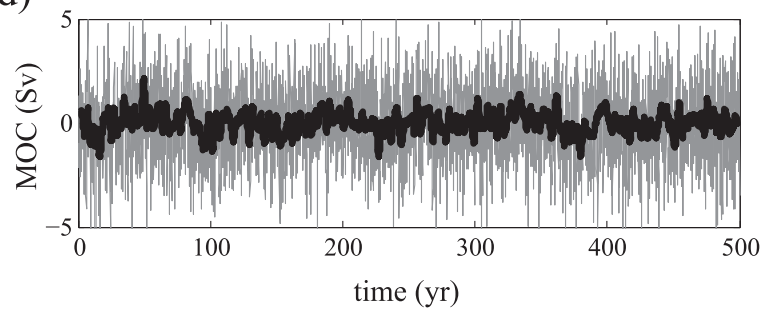

FIG. 2. Time series of anomalous (a) Agulhas leakage volume transport, $V_{\mathrm{ag}}$, as determined from the Lagrangian particle tracking analysis; (b) its associated salt flux $F_{S}$; (c) salinity at $37^{\circ} \mathrm{S}, 10^{\circ} \mathrm{E}$ in the South Atlantic, averaged over the upper $1500 \mathrm{~m} S_{1500}^{\text {ref }}$; and (d) the AMOC strength, as the maximum of the overturning streamfunction in the North Atlantic. Shown are monthly anomalies (with annual and semiannual cycles removed; gray) and low-pass filtered time series, retaining time scales of $10 \mathrm{yr}$ and longer (black). See text for details.

anomalies at $26^{\circ} \mathrm{N}$. They are coherent with the AMOC in the South Atlantic only on multidecadal time scales, with periods exceeding $50 \mathrm{yr}$ (Fig. 3b). This is consistent with the idea that the equator acts as a low-pass filter for AMOC anomalies propagating as waves (Johnson and Marshall 2002a,b, 2004). For this reason, we cannot expect variability in Agulhas leakage on interdecadal time scales to significantly affect the AMOC in the North Atlantic through wave adjustment.

Third, Fig. $3 \mathrm{c}$ shows the coherence between $F_{S}$ and the AMOC at select latitudes, namely $30^{\circ} \mathrm{S}$ (blue), $15^{\circ} \mathrm{S}$ (red), and $15^{\circ} \mathrm{N}$ (black). The coherences rise slightly above the significance limit for multidecadal time scales
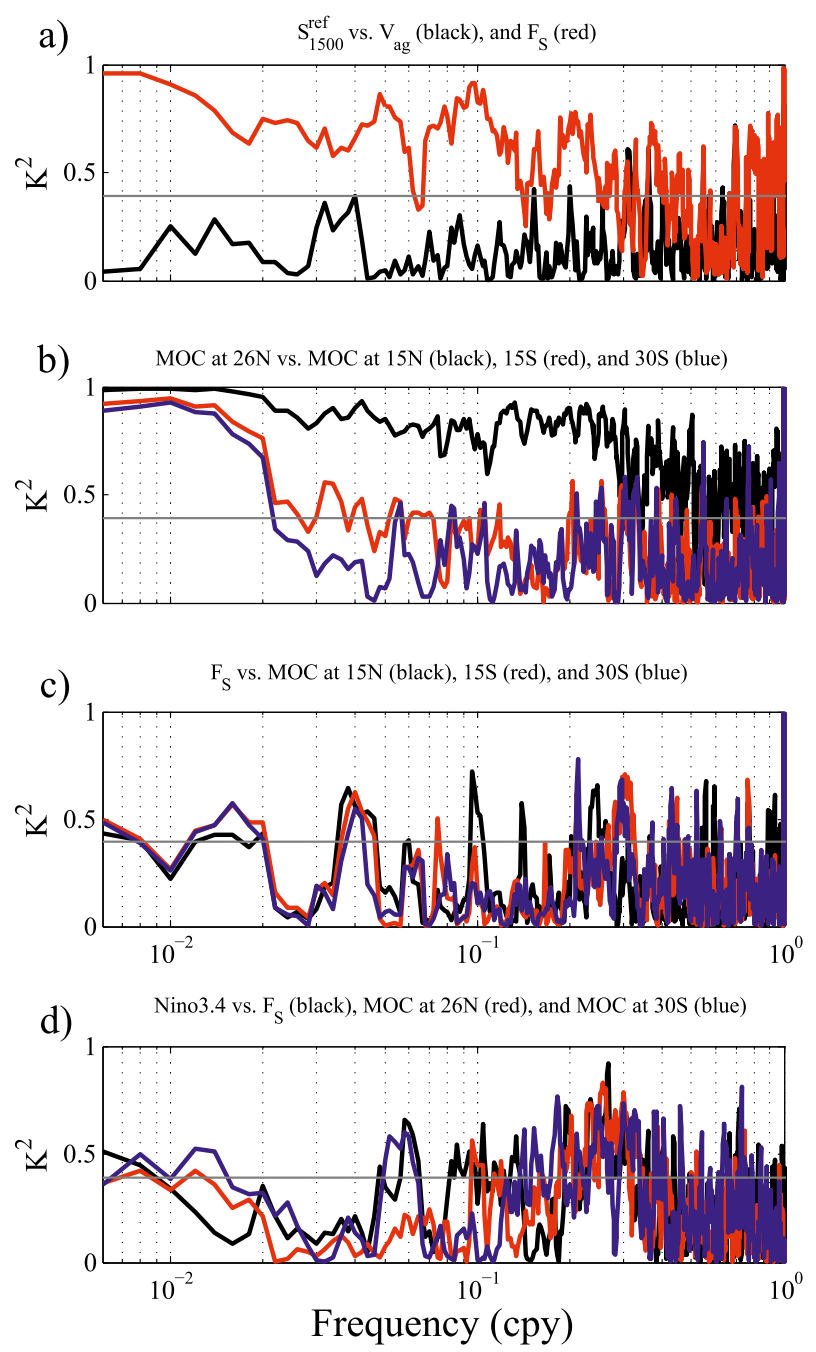

FIG. 3. (a) Coherence between $S_{1500}^{\text {ref }}$, and Agulhas leakage $V_{\text {ag }}$ (black) and its associated salt flux $F_{S}$ (red). (b) Coherence between the strength of the $\mathrm{AMOC}$ at $26^{\circ} \mathrm{N}$ and at $15^{\circ} \mathrm{N}$ (black), $15^{\circ} \mathrm{S}$ (red), and $30^{\circ} \mathrm{S}$ (blue). (c) Coherence between $F_{S}$ and the AMOC at $15^{\circ} \mathrm{N}$ (black), $15^{\circ} \mathrm{S}$ (red), and $30^{\circ} \mathrm{S}$ (blue). (d) Coherence between the Niño-3.4 index and $F_{S}$ (black), the AMOC at $26^{\circ} \mathrm{N}$ (red), and the $\mathrm{AMOC}$ at $30^{\circ} \mathrm{S}$ (blue). The gray lines represent the $95 \%$ confidence limit of nonzero coherence. A 7-point Daniell filter is applied to smooth the spectra.

(periods exceeding $50 \mathrm{yr}$ ); no significant coherences are found with the AMOC north of $35^{\circ} \mathrm{N}$. This signal might point to a causal relationship between salt flux variability and the strength of the AMOC in at least the South Atlantic. To investigate this further, we consider the coherence phase and associated time lag between $F_{S}$ and the AMOC as function of latitude (Fig. 4, black curves). Indeed, south of about $15^{\circ} \mathrm{S}$ the phase is negative, meaning that $F_{S}$ leads the AMOC as one would expect for a causal relationship. However, north of this latitude, $F_{S}$ seems to lag the AMOC. In fact, the phase 
a)

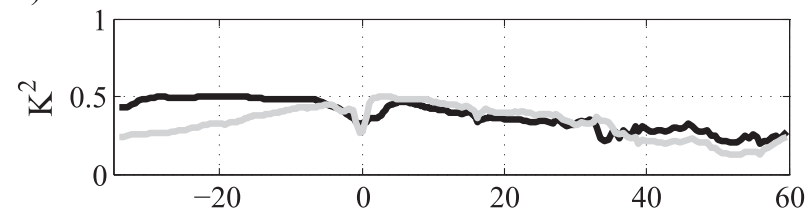

b)

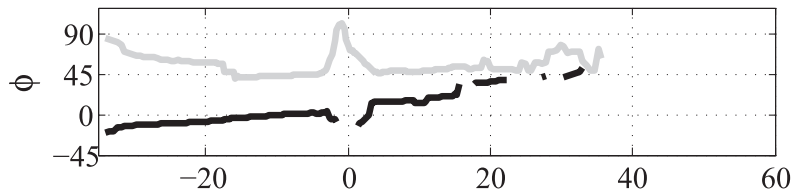

c)

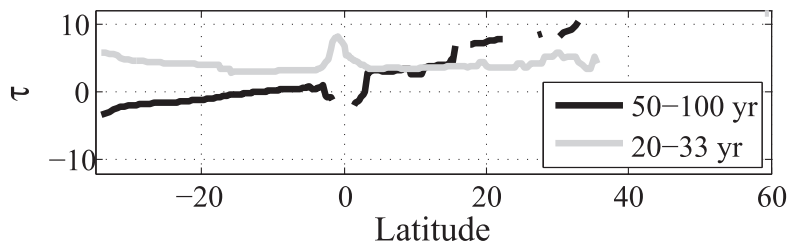

FIG. 4. (a) Coherence squared $K^{2}$, (b) coherence phase $\phi$, and (c) time lag $\tau(\mathrm{yr})$, between $F_{S}$ and AMOC strength as function of latitude, averaged over two frequency bands: $0.01-0.02$ (black) and $0.03-0.05$ cpy (gray). Negative phase and lag mean $F_{S}$ leads the AMOC. Phase and time lag are only averaged over frequency components that have a coherence significantly different from zero $\left(K^{2}>0.4\right)$.

progression when going northward is suggestive of a southward propagating signal with a transit time of about $15 \mathrm{yr}$ from $45^{\circ} \mathrm{N}$ to $30^{\circ} \mathrm{S}$. This is not consistent with an adjustment of the AMOC through northward advection of density anomalies introduced by Agulhas leakage. The adjustment of the AMOC through waves is a complicated process involving Kelvin and Rossby waves (Johnson and Marshall 2002a) and could in principle lead to an apparent southward propagation of AMOC anomalies in the South Atlantic. However, the adjustment in the North Atlantic should still proceed northward, in contrast to the result presented here. We therefore suspect that the coherence found in the multidecadal range reflects a southward propagating signal of the AMOC that affects $F_{S}$, or a joint response to a common forcing.

On decadal time scales, there is a narrow peak of significant coherences around the 25 -yr period. However, inspection of the phase between the time series indicates that $F_{S}$ lags the AMOC by about $4 \mathrm{yr}$ throughout the Atlantic, with no noticeable change in lag when going northward (Fig. 4, gray curves). For that reason it seems unlikely that Agulhas leakage is responsible for the variability in the MOC at $25 \mathrm{yr}$, but that both $\mathrm{AMOC}$ and $F_{S}$ vary in response to a common forcing instead.

The remaining time scales where significant coherences are found are between 3 and 5 yr. Further analysis (Fig. 3d)

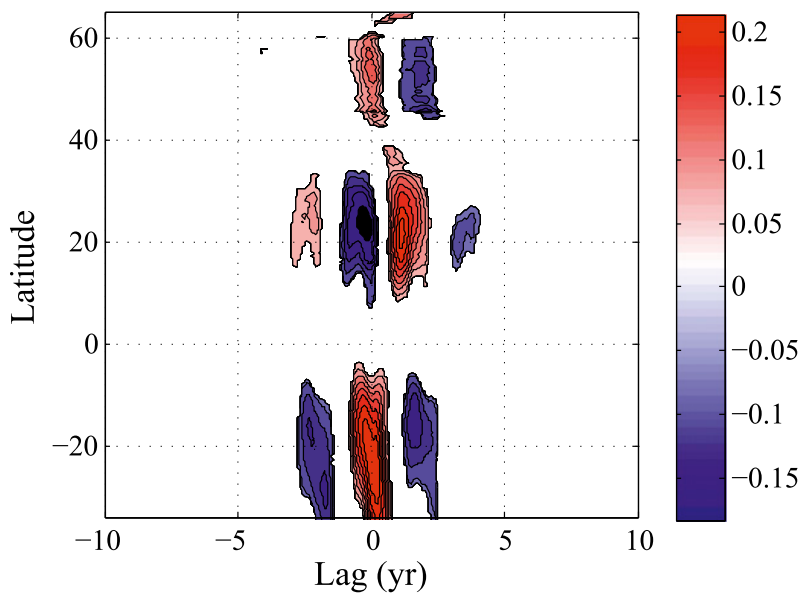

FIG. 5. Lagged correlations between the Niño-3.4 index and the strength of the AMOC as function of latitude in the Atlantic. Only correlations at the $95 \%$ significance level are shaded.

suggests that these coherences do not indicate a causal relationship but that both salinity and the AMOC time series are affected by the El Niño-Southern Oscillation phenomenon, the dominant mode of interannual variability in the climate of this model (Deser et al. 2012). In particular, Fig. 5 shows that the El Niño signal, represented here by the traditional Niño-3.4 index [SST averaged over a strip in the equatorial Pacific from $5^{\circ} \mathrm{S}$ to $5^{\circ} \mathrm{N}$ and from $170^{\circ}$ to $120^{\circ} \mathrm{W}$; Trenberth (1997)], has an equally strong and concurrent (but opposite in sign) impact on the AMOC in the subtropical regions of the South and North Atlantic.

This analysis of the coherences between the different time series thus suggests that Agulhas leakage, and the salinity anomalies that it introduces into the southeastern South Atlantic, does not affect the AMOC at any latitude in the CCSM4 on any time scale.

\section{b. Signal propagation}

The statistical analysis of the previous section does not suggest any consistent causal relationship between Agulhas leakage and the strength of the AMOC. The question is whether salinity anomalies introduced by Agulhas leakage actually make it far enough north to influence the AMOC in the North Atlantic. Here we investigate the propagation of signals introduced into the southeastern South Atlantic by calculating laggedcorrelation maps between $F_{S}$ and upper-ocean salinities $\left(S_{1500}\right)$ in the entire Atlantic. To focus on (inter)decadal time scales, we apply the following data processing steps (black lines in Fig. 2): 1) the mean and the annual and semiannual cycles are removed; 2) a low-pass Parks-McClellan filter of order 40 is applied, with high-frequency cut-off at $1 / 10$ cpy (Parks and McClellan 1972); 3) a fourth-order polynomial is fitted to, and 
subtracted from, the time series to remove the lowfrequency undulations; 4) the time series are detrended; and 5) the data are bin-averaged into 3-month bins. Lags between $\pm 75 \mathrm{yr}$ are probed. Testing of correlations being significantly larger than zero at the $95 \%$ level is based on the $t$ distribution (Von Storch and Zwiers 1999), and a rigorous determination of the number of degrees of freedom of the time series (based on the maximum of their decorrelation time scales, Gille 2005). Since our goal is to detect the propagation of salinity anomalies based on positive correlations between $F_{S}$ and $S_{1500}$ in the Atlantic, a one-sided significance test is appropriate; this test is less stringent than a two-sided test at the $95 \%$ level, which assumes that only $2.5 \%$ of the correlations of random time series test positive for a positive correlation.

Figure 6 shows the maximum correlation between $F_{S}$ and $S_{1500}$ probed for positive lags only, as well as the lag where this correlation is obtained. There are several areas of significant correlations found in the Atlantic. First of all, a west-northwestward-oriented plume of significant correlations arises in the Agulhas region, with lags increasing westward from 0 to about $3 \mathrm{yr}$ in the Brazil Current; this is consistent with an advective transport of salinity anomalies across the South Atlantic basin. Second, there is a patch of significant correlations in the eastern equatorial Atlantic, with relatively small lags of 3-5 yr. Third, a "ribbon" of significant correlations can be seen in the Caribbean Current and the Gulf Stream, at 35-36-yr lags. This connects, fourth, to a large area in the subtropical gyre of the North Atlantic with significant positive correlations. The smallest lags are $39 \mathrm{yr}$. Fifth, significant correlations as high as 0.3 are seen in the subpolar North Atlantic, with lags as short as $1 \mathrm{yr}$.

The correlations in the subpolar North Atlantic are too rapid to be explained by the advective mechanism and might, instead, reflect a joint response to a common forcing agent (such as ENSO). Evidence for a rapid wavelike response could not be found here and is expected to be weak, as argued in the previous section. However, the correlations linking the South Atlantic, the Brazil Current, the Caribbean, the Gulf Stream, and the subtropical North Atlantic are consistent with an advective mechanism. Still, the time scales for the anomalies to reach the North Atlantic (30-40 yr) seem rather long. We investigate the propagation of salinity anomalies in more detail from the Lagrangian perspective. In particular we would like to understand the transit times for particles to reach the North Atlantic. To that end, we followed the trajectories from the Good Hope line to three locations in the Atlantic (Fig. 7).

The trajectories arriving in the Brazil Current at $12^{\circ} \mathrm{S}$ have an average arrival time of about $20 \mathrm{yr}$, with the

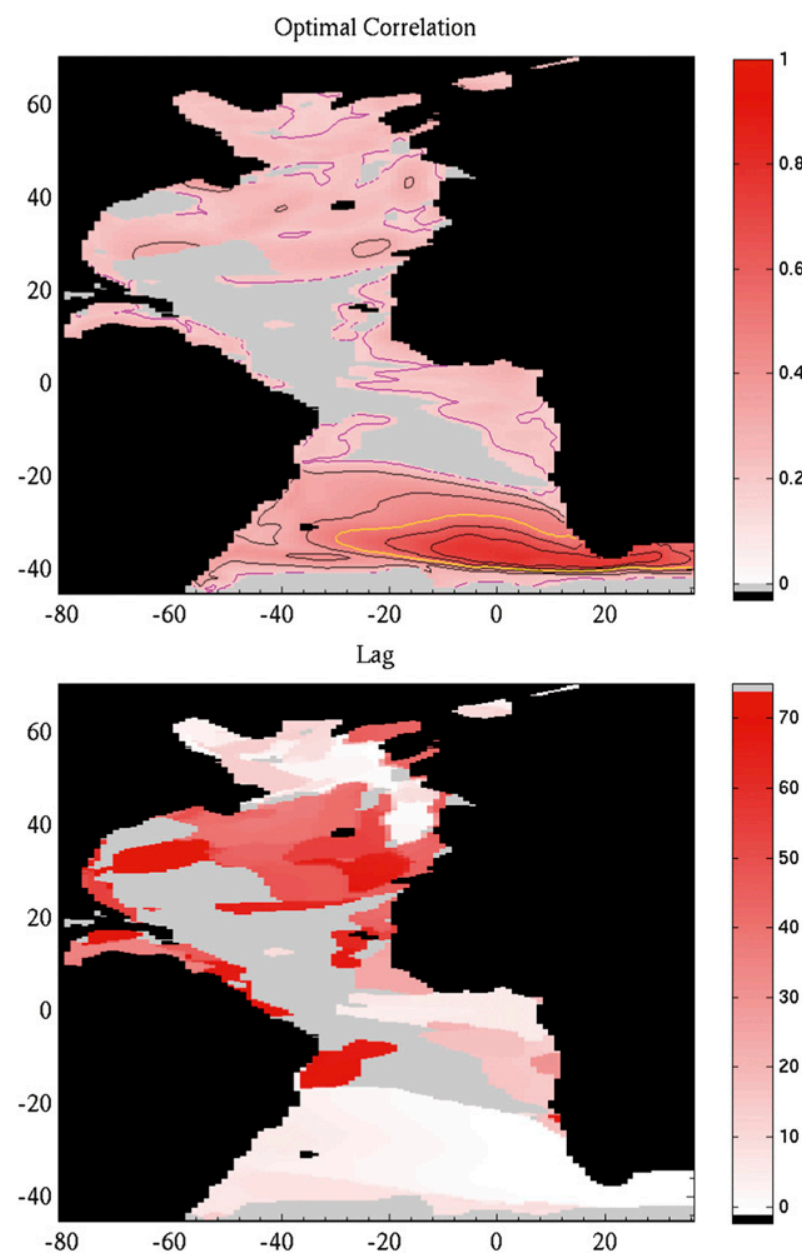

FIG. 6. (a) Map of the optimal correlation between $F_{S}$ and $S_{1500}$ in the Atlantic. Contour interval is 0.1, and contours with values of 0.5 (yellow) and 0.2 (magenta) are highlighted. Areas without any significant positive correlations are shaded gray. (b) The lag (yr) at which this optimal correlation is achieved.

largest wave of trajectories arriving after a decade. However, it takes particles on average $34 \mathrm{yr}$ to reach the southern Caribbean at $12^{\circ} \mathrm{N}$, with the majority arriving after $20 \mathrm{yr}$. This value is consistent with the lag of about $36 \mathrm{yr}$ for which the salinity field has the optimal correlation with $F_{S}$. Figure 8 shows the often circuitous routes taken by the particles before reaching the southern Caribbean. The arrival time distribution for the Gulf Stream centers around $30 \mathrm{yr}$, with an average of $40 \mathrm{yr}$ (assuming a lognormal fit to the distribution).

This analysis shows that the particles reach the Brazil Current fairly quickly, but that it takes almost a decade longer before a significant amount of the particles have entered the North Atlantic. Nonetheless, the particles appear able to carry their salinity anomaly from the Good Hope line to that region, and leave a significant imprint on the salinity field, as shown by Fig. 6 . 

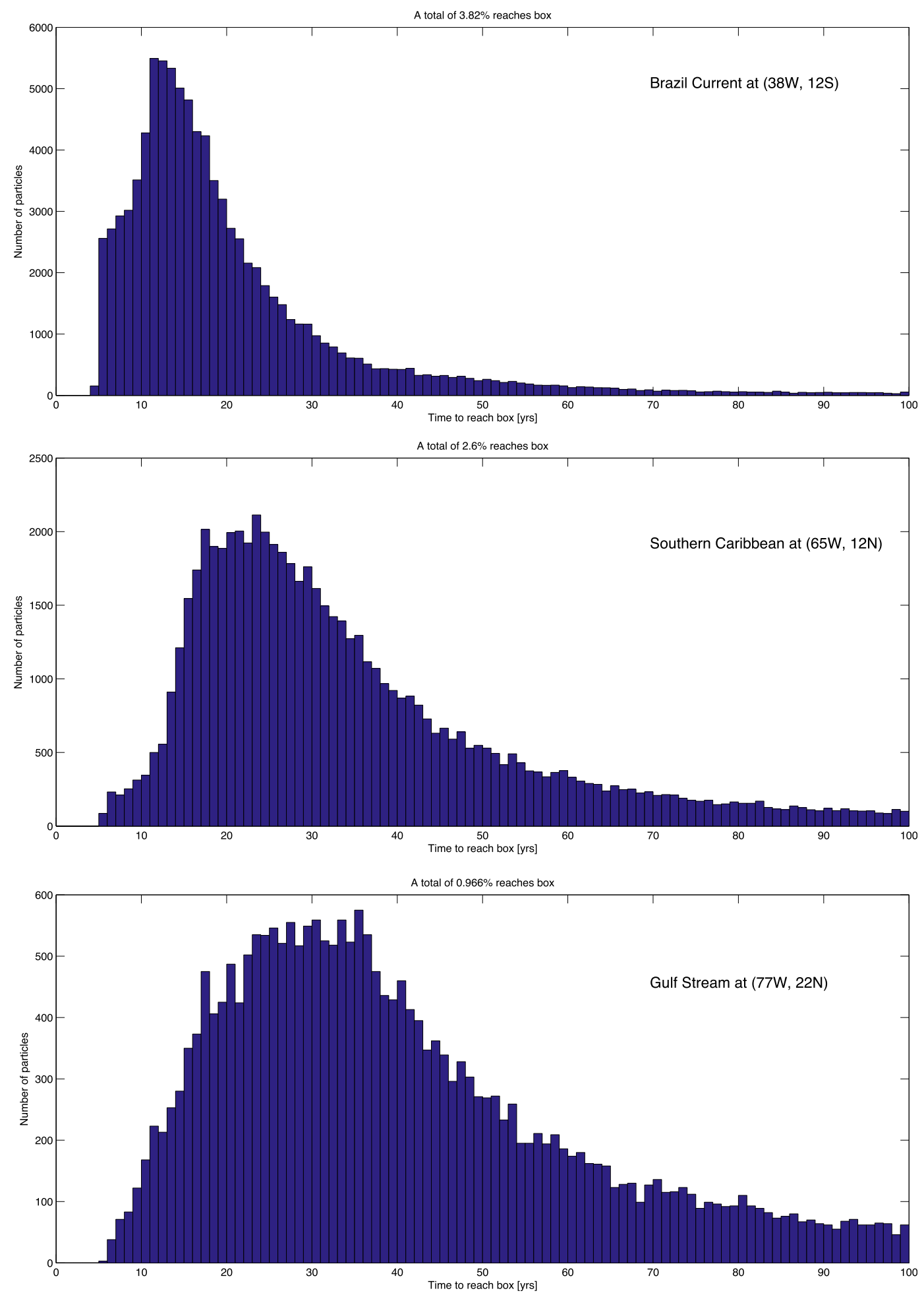

FIG. 7. Histograms of transit times of trajectories between the Good Hope line and three locations in the Atlantic, namely the Brazil Current $\left(12^{\circ} \mathrm{S}, 38^{\circ} \mathrm{W}\right)$, the southern Caribbean $\left(12^{\circ} \mathrm{N}, 65^{\circ} \mathrm{W}\right)$, and the Gulf Stream $\left(22^{\circ} \mathrm{N}, 77^{\circ} \mathrm{W}\right)$. 


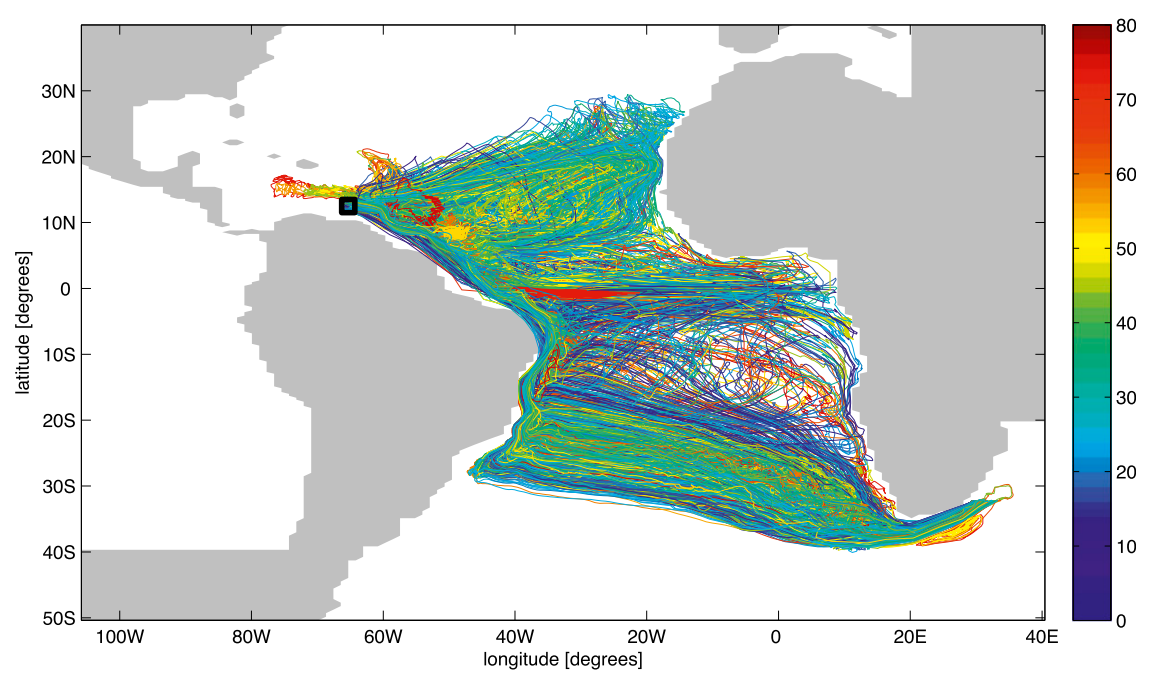

FIG. 8. A subset of trajectories that reach our target location in the southern Caribbean Sea at $12^{\circ} \mathrm{N}, 65^{\circ} \mathrm{W}$, indicated by the black square.

\section{Discussion}

Our analysis shows that an advective pathway exists in a coupled climate model that connects the Agulhas region with the North Atlantic, and through which salinity anomalies are advected. Characteristic time scales for these anomalies to reach the North Atlantic are typically on the order of 30-40 yr, consistent with the analysis by Biastoch and Böning (2013). Nonetheless, we found no clear causal relation between variability in Agulhas leakage and the strength of the AMOC. Apparently, the salinity anomalies that arrive in the northern North Atlantic are too weak in this model to have a measurable impact on the stratification, and hence on the AMOC. However, we are hesitant to conclude that variability in Agulhas leakage does not have an impact on the AMOC. As discussed below, significant salinity biases exist in the model that render the salinity anomalies introduced by Agulhas leakage to be much weaker than found in observations. It is possible that more significant variability in the Agulhas leakage salt flux may be able to exert an influence on the AMOC. Dedicated model experiments with the current model, or a long integration of an Agulhas leakage-resolving ocean model, would be required to settle this question.

It has been well established (e.g., Banks et al. 2007; Weijer et al. 2012) and it is dynamically well understood (De Ruijter 1982) that the Indian-Atlantic interocean exchange is overestimated in models that lack enough spatial resolution to properly represent the inertial dynamics of the Agulhas retroflection and ring shedding process; the wind-driven circulation systems of the southern Indian and South Atlantic Oceans [the so-called super gyre, Speich et al. (2007)] are too strongly coupled.
We suggest here that the overestimation of the interocean exchange in this model homogenizes the water mass characteristics of the South Atlantic and Indian Oceans, possibly exacerbating existing biases in these fields due to precipitation errors (Gent et al. 2011; Danabasoglu et al. 2012).

A look at the salinity difference between the southeastern South Atlantic and the southwestern section of the southern Indian Ocean provides support for this idea; Fig. 9 compares salinity averaged over the upper $1000 \mathrm{~m} S_{1000}$ for the CCSM4 and the Commonwealth Scientific and Industrial Research Organisation (CSIRO)

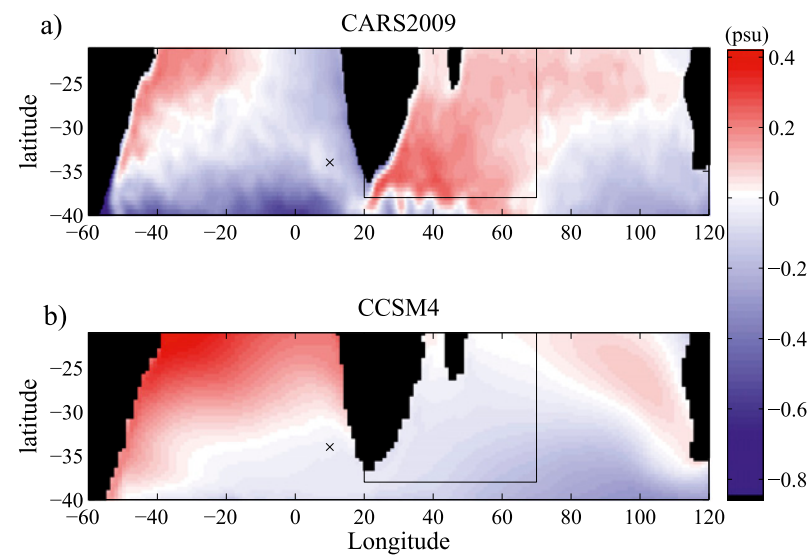

FIG. 9. Climatology of $S_{1000}$, for (a) CARS2009 and (b) CCSM4. Area-averaged salinity is subtracted from both datasets to emphasize spatial anomalies of the time-mean state. The black crosses indicate the location of a reference point at $34^{\circ} \mathrm{S}, 10^{\circ} \mathrm{E}$ in the southeastern South Atlantic, while the boxes represent the area of averaging in the southeastern section of the southern Indian Ocean referred to in the text. 
Atlas of Regional Seas (CARS2009) (Ridgway et al. 2002) climatology. CARS2009 clearly shows a sharp salinity front at the Agulhas retroflection, separating the salty subtropical waters of the southwestern section of the southern Indian Ocean from the relatively fresh waters in the southeastern South Atlantic. Such a front is totally absent in the CCSM4. The climatological value of $S_{1000}$ at $34^{\circ} \mathrm{S}, 10^{\circ} \mathrm{E}$ in the South Atlantic (indicated by crosses in Fig. 9) is 34.82 psu in CARS2009, while the average over the region $38^{\circ}-23^{\circ} \mathrm{S}, 20^{\circ}-70^{\circ} \mathrm{E}$ in the southeastern Indian Ocean (black boxes in Fig. 9) is 35.06 psu, a contrast of 0.24 psu. In the model, these values are 34.40 and $34.36 \mathrm{psu}$, a difference of only $-0.04 \mathrm{psu}$, with the Indian Ocean being fresher than the Atlantic. Indeed, the standard deviation of salinity, averaged over the upper $1000 \mathrm{~m}$ (note that the standard deviations - given for each level in the upper $1000 \mathrm{~m}$-are averaged here) is $0.11 \mathrm{psu}$ in CARS2009, compared to $0.02 \mathrm{psu}$ for the model. This suggests that salinity variability induced by Agulhas leakage is underestimated in the CCSM4, possibly by a factor of 5 .

We should note that this present study only addresses interdecadal variability in Agulhas leakage in a relatively constant control climate. The study, therefore, does not address the relation between Agulhas leakage and AMOC in a rapidly changing climate. As also stated in the introduction, there is strong evidence from paleoceanographic proxies that Agulhas leakage and AMOC strength are linked during rapid climate transitions. The associated changes in Agulhas leakage, however, are likely much larger than the interannual signal in CCSM4.

Acknowledgments. This research was supported by the Regional and Global Climate Prediction Program of the U.S. Department of Energy Office of Science. The Los Alamos National Laboratory (LANL) is operated by the Los Alamos National Security, LLC, for the National Nuclear Security Administration of the U.S. Department of Energy under Contract DE-AC5206NA25396. EvS was supported by the Australian Research Council via Grants DE130101336 and CE110001028. The CCSM4 data were obtained from the Earth System Grid. The Connectivity Modeling System (CMS) for the Lagrangian advection of particles most current development was funded by the NSF-OCE RAPID Award 1048697 to C. B. Paris. We thank Mat Maltrud, with help in the data preparation, Milena Veneziani, and Matthew Hecht of LANL, and two anonymous reviewers for useful comments on the manuscript.

\section{REFERENCES}

Ansorge, I. J., S. Speich, J. R. E. Lutjeharms, G. J. Goni, C. J. Rautenbach, P. W. Froneman, M. Rouault, and S. L. Garzoli,
2005: Monitoring the oceanic flow between Africa and Antarctica: Report of the first GoodHope cruise. S. Afr. J. Sci., 101, 29-35.

Banks, H. T., S. Stark, and A. B. Keen, 2007: The adjustment of the coupled climate model HadGEM1 toward equilibrium and the impact on global climate. J. Climate, 20, 5815-5826.

Beal, L. M., and Coauthors, 2011: On the role of the Agulhas system in global climate. Nature, 472, 429-436.

Berger, W. H., and G. Wefer, 1996: Expeditions into the past: Paleoceanographic studies in the South Atlantic. The South Atlantic, G. Wefer et al., Eds., Springer-Verlag, 363-410.

Biastoch, A., and C. W. Böning, 2013: Anthropogenic impact on Agulhas leakage. Geophys. Res. Lett., 40, 1138-1143, doi:10.1002/ grl.50243.

_ - — , and J. Lutjeharms, 2008: Agulhas leakage dynamics affects decadal variability in Atlantic overturning circulation. Nature, 456, 489-492.

Cunningham, S. A., and Coauthors, 2007: Temporal variability of the Atlantic meridional overturning circulation at $26.5^{\circ} \mathrm{N}$. Science, 317, 935-938.

Danabasoglu, G., S. C. Bates, B. P. Briegleb, S. R. Jayne, M. Jochum, W. G. Large, S. Peacock, and S. G. Yeager, 2012: The CCSM4 ocean component. J. Climate, 25, 1361-1389.

De Ruijter, W., 1982: Asymptotic analysis of the Agulhas and Brazil current systems. J. Phys. Oceanogr., 12, 361-373.

A. Biastoch, S. S. Drijfhout, J. R. E. Lutjeharms, R. P. Matano, T. Pichevin, P. J. van Leeuwen, and W. Weijer, 1999: Indian-Atlantic interocean exchange: Dynamics, estimation and impact. J. Geophys. Res., 104 (C9), 20 885-20910.

Deser, C., and Coauthors, 2012: ENSO and Pacific decadal variability in the Community Climate System Model version 4 . J. Climate, 25, 2622-2651.

Gent, P. R., and J. C. McWilliams, 1990: Isopycnal mixing in ocean circulation models. J. Phys. Oceanogr., 20, 150-155.

, and Coauthors, 2011: The Community Climate System Model version 4. J. Climate, 24, 4973-4991.

Gille, S. T., 2005: Statistical characterization of zonal and meridional ocean wind stress. J. Atmos. Oceanic Technol., 22, 1353 1372

Gladyshev, S., M. Arhan, A. Sokov, and S. Speich, 2008: A hydrographic section from South Africa to the southern limit of the Antarctic circumpolar current at the Greenwich meridian. Deep-Sea Res. I, 55, 1284-1303.

Heimbach, P., C. Wunsch, R. M. Ponte, G. Forget, and J. Utke, 2011: Timescales and regions of the sensitivity of Atlantic meridional volume and heat transport: Toward observing system design. Deep-Sea Res. II, 58, 1858-1879.

Johnson, H. L., and D. P. Marshall, 2002a: A theory for the surface Atlantic response to thermohaline variability. J. Phys. Oceanogr., 32, 1121-1132.

, and - 2002b: Localization of abrupt change in the North Atlantic thermohaline circulation. Geophys. Res. Lett., 29, doi:10.1029/2001GL014140.

$\longrightarrow$, and - 2004: Global teleconnections of meridional overturning circulation anomalies. J. Phys. Oceanogr., 34, 17021722.

Knorr, G., and G. Lohmann, 2003: Southern Ocean origin for the resumption of Atlantic thermohaline circulation during deglaciation. Nature, 424, 532-536.

Paris, C. B., J. Helgers, E. van Sebille, and A. Srinivasan, 2013: Connectivity Modeling System: A probabilistic modeling tool for the multi-scale tracking of biotic and abiotic variability in the ocean. Environ. Modell. Software, 42, 47-54. 
Parks, T. W., and J. H. McClellan, 1972: Chebyshev approximation for nonrecursive digital filters with linear phase. IEEE Trans. Circuit Theory, 19, 189-194.

Peeters, F. J. C., R. Acheson, G. J. A. Brummer, W. P. M. de Ruijter, R. R. Schneider, G. M. Ganssen, E. Ufkes, and D. Kroon, 2004: Vigorous exchange between the Indian and Atlantic Oceans at the end of the past five glacial periods. Nature, 430, 661-665.

Richardson, P. L., 2007: Agulhas leakage into the Atlantic estimated with subsurface floats and surface drifters. Deep-Sea Res. I, 54, 1361-1389.

Ridgway, K. R., J. R. Dunn, and J. L. Wilkin, 2002: Ocean interpolation by four-dimensional weighted least squaresApplication to the waters around Australia.J. Atmos. Oceanic Technol., 19, 1357-1375.

Smith, R., and Coauthors, 2010: The Parallel Ocean Program (POP) reference manual. Los Alamos National Laboratory Tech. Rep., 141 pp.

Speich, S., and M. Arhan, 2007: Good-Hope/Southern Ocean: A study and monitoring of the Indo-Atlantic connections through the Southern Ocean. Mercator Ocean Quarterly Newsletter, No. 27, Ramonville-Saint-Agne, France, 29-41.

, B. Blanke, and W. Cai, 2007: Atlantic meridional overturning circulation and the Southern Hemisphere supergyre. Geophys. Res. Lett., 34, L23614, doi:10.1029/2007GL031583.
Trenberth, K. E., 1997: The definition of El Niño. Bull. Amer. Meteor. Soc., 78, 2771-2777.

- , and A. Solomon, 1994: The global heat balance: Heat transports in the atmosphere and ocean. Climate Dyn., 10, 107-134.

van Sebille, E., and P. J. van Leeuwen, 2007: Fast northward energy transfer in the Atlantic due to Agulhas rings. J. Phys. Oceanogr., 37, 2305-2315.

,-- , A. Biastoch, and W. P. M. de Ruijter, 2010: Flux comparison of Eulerian and Lagrangian estimates of Agulhas leakage: A case study using a numerical model. Deep-Sea Res. I, 57, 319-327.

von Storch, H., and F. W. Zwiers, 1999: Statistical Analysis in Climate Research. Cambridge University Press, 484 pp.

Weijer, W., W. P. M. De Ruijter, H. A. Dijkstra, and P. J. van Leeuwen, 1999: Impact of interbasin exchange on the Atlantic overturning circulation. J. Phys. Oceanogr., 29, 2266-2284. ,$- \ldots$, and $\longrightarrow$, 2001: Stability of the Atlantic overturning circulation: Competition between Bering Strait freshwater flux and Agulhas heat and salt sources. J. Phys. Oceanogr., 31, 23852402.

,,-- A. Sterl, and S. S. Drijfhout, 2002: Response of the Atlantic overturning circulation to South Atlantic sources of buoyancy. Global Planet. Change, 34, 293-311.

_ and Coauthors, 2012: The Southern Ocean and its climate in CCSM4. J. Climate, 25, 2652-2675. 